\title{
Comparative analysis of the properties of the nodular cast iron with carbides and the austempered ductile iron with use of the machine learning and the support vector machine
}

\author{
Dorota Wilk-Kolodziejczyk $^{1,2} \cdot$ Krzysztof Regulski $^{1} \cdot$ Grzegorz Gumienny $^{3}$
}

Received: 16 September 2015 / Accepted: 12 February 2016 / Published online: 9 March 2016

(C) The Author(s) 2016. This article is published with open access at Springerlink.com

\begin{abstract}
The use of modern casting materials allows the achievement of higher product quality indices. The conducted experimental studies of new materials allow obtaining alloys with high performance properties while maintaining low production costs. Studies have shown that in certain areas of applications, the expensive to manufacture austempered ductile iron (ADI) can be replaced with ausferritic ductile iron or bainitic nodular cast iron with carbides, obtained without the heat treatment of castings. The dissemination of experimental results is possible through the use of information technologies and building applications that automatically compare the properties of materials, as the machine learning tools in comparative analysis of the properties of materials, in particular ADI and nodular cast iron with carbides.
\end{abstract}

Keywords Austempered ductile iron(ADI) - Nodularcastiron with carbides (NCIC) · Cast iron · Data mining · Machine learning $\cdot$ Support vector machine

\section{Introduction}

Ductile iron continues being one of the most dynamically developing cast materials in the world. It is used by engineers as a preferred material for parts of the machinery and equipment. This forces the need to improve its functional properties

Dorota Wilk-Kolodziejczyk

dwilk@agh.edu.pl

\footnotetext{
AGH University of Science and Technology, Krakow, Poland

Foundry Research Institute, Krakow, Poland

Lodz University of Technology, Lodz, Poland
}

through the development of new types of ductile iron, satisfying the high demands of customers.

Studies to improve the properties of ductile iron have led to the development of materials such as austempered ductile iron (ADI) or ausferritic nodular cast iron with carbides (NCIC). The microstructure of these materials ensures high properties both mechanical and functional. An advanced variation of ADI is carbidic austempered ductile iron (CADI), which offers an increased resistance to wear. The required properties of this material are obtained, like in the case of ADI, by heat treatment of castings [1-5].

ADI is obtained by a heat treatment, which consists in quenching and isothermal holding in a temperature range of $250-400{ }^{\circ} \mathrm{C}$. A unique combination of these cast iron properties, including the strength, ductility, and fatigue behavior, makes this material a successful substitute for steel components or even aluminum alloys. ADI has a high fatigue strength higher than aluminum and is resistant to abrasive and adhesive wear [5, 6], but above all, its use can significantly reduce production costs by approx. $20 \%$ compared with wrought steel and $50 \%$ compared with aluminum. Another important feature is the cost of heat treatment lower than, for example, the cost of carburizing. Besides, the mere process of making iron castings is cheaper than the cost of making steel castings (lower energy consumption), not to mention even the forged steel, in the case of which the cost of production is additionally increased by the operation of plastic forming. ADI without heat treatment has better machinability, which increases tool life. On the other hand, finished items have the mechanical properties similar to numerous steel grades, while being approx. $10 \%$ lighter $[6,7]$.

The technologically demanding process to obtain ADI is an example of how important is accurate information about the individual process parameters. Parameters such as the temperature and time in different phases of the process, and also the 
chemical composition, strongly influence the final properties of the material.

An alternative way of obtaining the bainitic or ausferritic microstructure is by introducing elements that affect the austenite stability. In this way, an ausferritic or bainitic NCIC is obtained. The change in the microstructure caused by the use of alloying elements allows eliminating the costly heat treatment. Isothermal transformation is necessary in the manufacturing process of ADI significantly increasing the total cost of production. The results reviewed in this article show beneficial effect of alloying elements on the microstructure of ductile iron, which means the possibility of obtaining either bainitic or ausferritic matrix with carbides increasing the wear resistance [8-14].

The studies of wear resistance indicate that the developed ductile iron with carbides can successfully be used for machine parts, which are required to offer high resistance to wear, replacing in this way, e.g., castings made of ADI $[5,6]$.

Wear resistance as an important factor in the choice of construction material is but only one in the vast range of other material properties. In product design, the technologist must take into account a number of other criteria comprised in the technical requirements. Some materials, although significantly different from each other in terms of, e.g., density, may have similar characteristics as regards their mechanical properties and as such can be interchangeably taken into account in the design of products. Each product must meet some specific requirementssometimes the critical factor will be appropriate damping capacity, and in other cases, it may be the wear resistance.

Promoting new materials requires adequate dissemination of information, best achieved with the use of modern computer technology. Providing precise information can support the more frequent choice of particular material. A tool for the efficient and automatic classification of materials will serve as an aid supporting decisions regarding the selection of construction materials. In this way, the technologist will be able to make the best choice from among the wide range of various, but often similar, materials that meet the most demanding technological criteria, such as the tensile strength $\left(R_{\mathrm{m}}\right)$, the force needed to break the material sample, and yield strength $\left(R_{\mathrm{p} 0.2}\right)$, the stress a material can withstand without permanent deformation, elongation $(A)$, and hardness (HB). At this point, the problem is how to determine which materials can be classified as "similar." This is a simple task in the case of two or three parameters, but with an increasing number of attributes and the number of materials taken into account, it becomes a multicriteria analysis. Without calculations, the issue becomes quite difficult to comprehend, even for the technologist, let alone for stakeholders such as customers or persons preparing the offer.

Here come to the rescue the data mining tools and machine learning techniques drawing inspiration from the studies of artificial intelligence. The paper will present the use of a number of algorithms for classification, taking into account their effectiveness in solving the stated problem characterized by a strong non-linearity.

In the former authors' research, the problems of multicriteria decision support based on discrete and continuous signals were investigated with a possibility of use of the artificial intelligence methods in the domain of foundry engineering and metal processing. Those solutions were widely discussed in $[15,16]$ where an application of decision trees was presented in the conditions of metal processing and process optimization and in [17-19] where casting defects were indentified and classified with data mining techniques. Also a problem of knowledge representation was studied within those works in the context of data acquisition and integration in order to further process information [20-22]. The reasoning models based on one of logic knowledge representationslogic of plausible reasoning - were widely described in [23, 24]. An artificial intelligence was successfully applied in the systems of pattern recognition and diagnostics - an important domain of industry processes [25-27].

The problem in the analysis of experimental data is often the acquisition of the data needed for research. An invaluable source of data that until recently was not taken into account in research activities is the Internet. Searching for information to select process parameters and support the decision-making procedure is becoming nowadays more and more difficult due to the dispersion of research centers, a variety of sources (researchers, technologists, magazines, books, research reports, results of experiments), even in a niche so small as the production of ADI. Increasingly, all these sources of information can be found on the World Wide Web, but to accomplish this, it is often not enough to use Google.com, and even if it is, the task may turn out to be quite difficult [28, 29].

The proposed analysis is done by two routes, and one of them is to examine the problem of classification based on the raw data concerning various properties. This method can be improved by a preliminary analysis of clusters based on properties, making classification more rough but at the same time flawless (Fig. 1).

\section{The results of experiments with different materials}

\subsection{NCIC}

The base cast iron was melted in an electric medium frequency induction furnace. The charge was composed of pig iron of a special chemical composition presented in Table 1 and S235JR steel scrap with chemical composition according to the PN-EN 10025-1:2007 standard.

The content of silicon and manganese was adjusted with the addition of FeSi75 and FeMn75, respectively. The chemical composition of cast iron was examined with a SPECTROMAXx emission spectrometer provided with spark 
Fig. 1 Diagram of the process of modelling the problem of the selection of material based on required properties

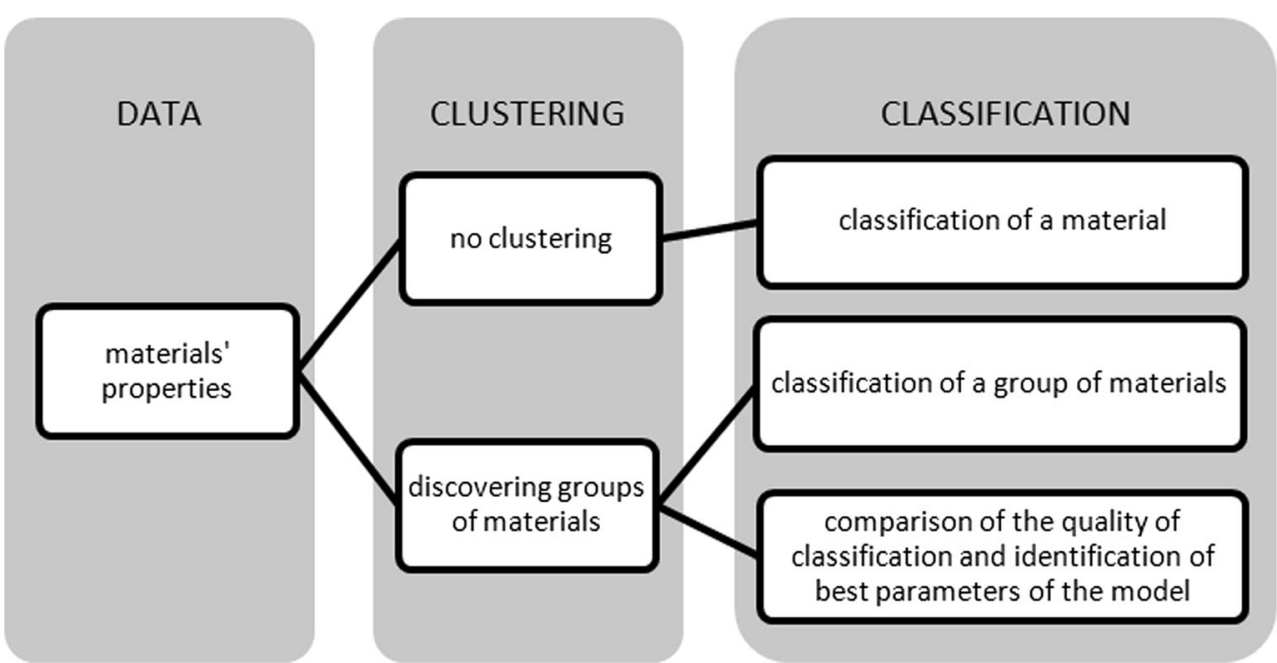

excitation from SPECTRO Analytical Instruments GmbH. The spheroidization of cast iron was made by Inmold process, using Lamet ${ }^{\circledR} 5504$ master alloy from the Norwegian Elkem Company. The chemical composition of the master alloy is shown in Table 2.

Due to its strong inoculating effect, the master alloy used for the Inmold spheroidizing treatment has provided a high degree of the refinement of eutectic grains in the tested ductile iron. This produced a large number of fine eutectic grains and carbides. This is important for the castings whose functional properties are to be achieved in as-cast condition, i.e., without the use of heat treatment.

In the study, the data was collected from 150 melts. As alloying additions, elements such as copper, nickel, molybdenum, and chromium were used in concentrations strictly dependent on the effect they exert on the microstructure and properties of cast iron. The additions of $\mathrm{Mo}, \mathrm{Cr}, \mathrm{Ni}$, and $\mathrm{Cu}$ enable obtaining the ductile iron whose metallic matrix is based on bainite, ausferrite, martensite, or a mixture of these constituents, additionally containing carbides to increase the wear resistance without subjecting the casting to a heat treatment. The effect of various alloying elements on the microstructure and properties of cast iron was investigated. (1) Due to its pearlitizing effect, the addition of copper greatly reduces the temperature of the beginning of austenite transformation. The addition of copper resulted in the disappearance of ferrite and in the formation of a pearlitic microstructure of the metal matrix in the entire examined range of the casting wall thickness values. (2) The addition of nickel raised the temperature

Table 1 Chemical composition of special pig iron
Chemical composition, wt $\%$

\begin{tabular}{lllll}
\hline $\mathrm{C}$ & $\mathrm{Si}$ & $\mathrm{Mn}$ & $\mathrm{P}$ & $\mathrm{S}$ \\
\hline 4.44 & 0.69 & 0.025 & 0.046 & 0.009 \\
\hline
\end{tabular}

of the eutectic transformation by approx. $6^{\circ} \mathrm{C}$ (slightly smaller increase than that observed in the cast iron containing $\mathrm{Cu}$ ). This is due to the graphitizing effect of an intensity similar to $\mathrm{Cu}$. Compared with unalloyed cast iron, nickel reduces the tendency to the matrix ferritization. However, in the case under discussion, this effect was weaker compared to the cast iron containing copper, because in castings with the examined range of wall thickness values, the graphite nodules were surrounded by the precipitates of ferrite. (3) Compared to unalloyed cast iron, the addition of $1.5 \%$ molybdenum resulted in a significant drop of the crystallization temperature of the eutectic (by approx. $16^{\circ} \mathrm{C}$ ). (4) The addition of $\mathrm{Cr}$ reduced the temperature of the eutectic crystallization by about $10{ }^{\circ} \mathrm{C}$, compared to the unalloyed cast iron, but the drop was smaller than in the cast iron containing similar amount of Mo. Chromium intensively raises the temperature of the pearlitic transformation in nodular cast iron. The addition of about $1.5 \% \mathrm{Cr}$ favors matrix pearlitization and promotes carbide formation in the microstructure of the cast iron metal matrix.

Studies have shown that to produce upper bainite in the matrix of nodular cast iron with carbides, it was necessary to introduce a combined addition of molybdenum and nickel. Molybdenum concentration was changing in the range of 1.3 to $2.1 \%$ with nickel content comprised in the range of $0.7-1.1 \%$ (depending on the casting wall thickness and concentration of other elements). Depending on the concentration of $\mathrm{Mo}, \mathrm{Ni}$, and $\mathrm{Cr}$, the surface content of carbides in the cast

Table 2 Chemical composition of the spheroidizing-inoculating master alloy [1]

Chemical composition, wt $\%$

\begin{tabular}{llllll}
\hline $\mathrm{Si}$ & $\mathrm{Mg}$ & $\mathrm{Ca}$ & $\mathrm{La}$ & $\mathrm{Al}$ & $\mathrm{Fe}$ \\
\hline $44-48$ & $5-6$ & $0.4-0.6$ & $0.25-0.40$ & $0.8-1.2$ & Rest \\
\hline
\end{tabular}


iron was from 0 to about $12 \%$; the content higher than $5 \%$ resulted in a significant drop of ductility. The microstructure of upper bainite without the inclusions of other phases was obtained in the nodular cast iron with carbides for the following range of the chemical composition (wt \%): $\mathrm{C}=3.27-$ $3.91 \%, \mathrm{Si}=2.23-2.56 \%, \mathrm{Mn}=0.05-0.09 \%, \mathrm{Cr}=0.00$ $0.28 \%, \mathrm{Mo}=1.87-2.13 \%$, and $\mathrm{Ni}=0.66-1.05 \%$. Due to the increased content of carbides in thin-walled castings, Mo concentration could be reduced to about $1.5 \%$. This reduced the surface content of carbides to about $5 \%$ and increased the ductility.

To obtain in the cast iron metal matrix the structure of upper bainite without carbide precipitates, molybdenum concentration was decreased to about $1.3 \%$. The maximum tensile strength of the nodular cast iron with carbides and the upper bainite was about $1000 \mathrm{MPa}$ at an elongation of about 3-4\%. At a $6 \%$ elongation, the value of $R_{\mathrm{m}}$ was $750 \mathrm{MPa}$ with the yield strength of $500 \mathrm{MPa}$.

The cast iron with a metal matrix microstructure composed of upper bainite, lower bainite, and carbides had slightly higher mechanical properties. This was due to the nickel concentration raised to about $1.5 \%$ with molybdenum concentration similar as in the cast iron with upper bainite. In thinwalled castings, the concentration of nickel should be lower, considering the high cooling rate and the possibility of martensite formation. The range of the chemical composition for the nodular cast iron with carbides and a mixture of upper and lower bainite was as follows (wt \%): $\mathrm{C}=3.57-3.83 \%$, $\mathrm{Si}=2.36-2.87 \%$, Mn 0.05-0.09\%, $\mathrm{Cr}=0.00-0.34 \%$, $\mathrm{Mo}=1.91-2.05 \%$, and $\mathrm{Ni}=1.33-1.62 \%$. It allowed obtaining the cast iron with a tensile strength $R_{\mathrm{m}}$ in the range of 850-1050 MPa at an elongation $A$ of 4-2 \%.

Introducing to the cast iron with molybdenum, small (about $0.5 \%$ ) quantities of chromium and copper in a concentration of 1.3-2.0\% produced ausferrite and carbides in the metal matrix without the need for the heat treatment of castings. Depending on the cooling rate (casting wall thickness), the ausferritic microstructure of nodular cast iron with carbides was obtained for the following range of chemical composition (wt \%): $\mathrm{C}=3.53-3.84 \%, \mathrm{Si}=2.40-2.63 \%$, Mn 0.28-0.34\%, $\mathrm{Mo}=1.41-1.62 \%, \mathrm{Cr}=0.45-0.55 \%$, and $\mathrm{Cu}=1.03-2.08 \%$. In thin-walled castings, ausferrite was obtained with copper content in the lower limit of the specified range. In the castings with a wall thickness of $25 \mathrm{~mm}$, the minimum $\mathrm{Cu}$ content necessary to obtain ausferrite free from the precipitates of pearlite was $1.5 \%$. Increasing the concentration of $\mathrm{Cu}$ to about $2.0 \%$ did not cause the despheroidization of the nodular graphite.

Among the investigated types of nodular cast iron with carbides, the cast iron with an ausferritic microstructure of the metal matrix had the highest strength properties. Its tensile strength $\left(R_{\mathrm{m}}\right)$ varied between 750 and $1100 \mathrm{MPa}$ at an elongation $(A)$ of 6 to $3 \%$, respectively. The hardness in Brinell scale (HB) of ausferritic cast iron was from 280 to $345 \mathrm{HB}$ units and was by up to $40 \mathrm{HB}$ units lower than the hardness of the cast iron with upper bainite.

The presence of carbides in the ductile iron metal matrix is expected to increase the resistance to abrasive and adhesive wear compared with other, currently used, types of cast iron. The abrasive and adhesive wear of the newly developed cast iron grades was compared with the grades used so far, ADI included. The effect of the surface content of carbides on the cast iron wear resistance was examined [11, 14]. In this group of materials, ADI had the lowest hardness among all the examined cast iron grades. The cast iron with upper bainite matrix exhibited a slightly higher hardness of $272 \mathrm{HB}$ units. Carbides in the content of 5 and $12 \%$ increased the hardness of this cast iron to 293 and $411 \mathrm{HB}$ units, respectively. The cast iron with the matrix composed of a mixture of upper bainite, lower bainite, and carbides was characterized by the highest hardness of $477 \mathrm{HB}$ units.

The mechanical properties of nodular cast iron with carbides depend on the type of metal matrix and on the carbide content. The conducted studies have shown that surface content of carbides higher than $5 \%$ causes a significant decrease in plastic properties regardless of the type of metal matrix. It has been found that the small fraction of carbides in the matrix, reducing only slightly the cast iron ductility, significantly raises the resistance to both abrasive and adhesive wear. The examined cast iron was divided into five groups (from I to V) depending on the matrix microstructure. The surface content of carbides in each examined cast iron group was up to $5 \%$. Table 3 shows the basic mechanical properties of different types of the nodular cast iron with carbides.
Table 3 Mechanical properties of nodular cast iron with carbides

\begin{tabular}{|c|c|c|c|c|c|}
\hline \multirow[t]{2}{*}{ Group no. } & \multirow[t]{2}{*}{ Matrix type } & \multicolumn{4}{|c|}{ Mechanical properties } \\
\hline & & $R_{\mathrm{m}}, \mathrm{MPa}$ & $R_{\mathrm{p} 0,2}, \mathrm{MPa}$ & $A, \%$ & HB \\
\hline I & Pearlite & $450-700$ & $330-450$ & $2-5$ & $270-375$ \\
\hline II & Upper bainite & $750-1000$ & $500-750$ & $3-6$ & $285-385$ \\
\hline III & Upper bainite with lower bainite & $850-1050$ & $650-800$ & $2-4$ & $380-490$ \\
\hline IV & Martensite & $780-950$ & $500-700$ & $<2$ & $470-570$ \\
\hline V & Ausferrite & $750-1100$ & $500-700$ & $3-6$ & $280-345$ \\
\hline
\end{tabular}


The cast iron with a pearlitic matrix and carbides (group I) showed the lowest strength properties, while the highest tensile strength was obtained in the ausferritic cast iron with carbides (group V). The highest elongation was obtained in the nodular cast iron with carbides in which the matrix was composed of upper bainite and ausferrite (groups II and V, respectively). The ductile iron free from the carbide precipitates showed elongation higher by maximum $2 \%$. The relatively large discrepancy in the minimum and maximum properties within a given group was mainly caused by the surface content of carbides varying between 2 and $5 \%$.

Through the introduction of alloying elements, such as Mo, $\mathrm{Cr}, \mathrm{Cu}$, and $\mathrm{Ni}$, it is possible to obtain bainite or ausferrite in the cast iron without any heat treatment. This is due to the impact of these elements on the time-temperature-transformation (TTT) curves. Each of the abovementioned elements makes the curve of the start of austenite decomposition shift towards longer times, the influence most intensive being that of nickel. Copper impact on the stability of austenite is less intense. Chromium and molybdenum are carbide-forming elements, but to some extent, they can dissolve in austenite, thus affecting its stability. A very characteristic effect is that of molybdenum, which enhances the stability of austenite with respect to its transformation to pearlite. Nevertheless, molybdenum does not affect in a more significant manner the stability in a bainitic range. Figure 2 shows the CCT curves of cast iron containing about $0.5 \% \mathrm{Cr}, 1.4 \% \mathrm{Mo}$, and $1 \% \mathrm{Cu}$. The graph was plotted using the following cooling rates of samples: $6,8,10,15,20,30,40,50,60,75,90,105,120,150$,
$180,210,240,270,300,330,360,402,450,510,600,900$, and $1620^{\circ} \mathrm{C} / \mathrm{min}$. The specified chemical composition enabled obtaining in the base cast iron for dilatometric tests a metal matrix composed of ausferrite and carbides in castings with the wall thickness of 3 to $25 \mathrm{~mm}$. The TTT graphs of selected cast iron grades were plotted using a RITA L78 High Speed Quenching Dilatometer made by LINSEIS Company. The HV30 hardness measurements were taken on samples used for plotting of the TTT curves with a Dia Tester 2R made by Wolpert-Werke (Germany) under a load of $294.2 \mathrm{~N}$ (HV30). The measurement was performed in accordance with the PN-EN ISO 6507-1 standard.

From the graphs, it follows that in the area of pearlitic transformation (upper marked region), the stability of austenite is similar to the stability in bainitic area (lower marked region). This is due to a reduced concentration of molybdenum and the addition of $\mathrm{Cu}$, which is less effective than nickel in enhancing the stability of austenite in the range of pearlitic transformation. There is, however, a range of cooling speeds, which promotes the occurrence of bainitic transformation without the need of crossing the pearlitic area. The impact of copper on the beginning of austenite decomposition in a bainitic range is much more intense than that of nickel. In the examined cast iron, the martensitic microstructure was obtained in the range of cooling speeds of $360-1620{ }^{\circ} \mathrm{C} / \mathrm{min}$. Pearlite precipitates occurred in the metal matrix of cast iron cooled at a rate of $210{ }^{\circ} \mathrm{C} / \mathrm{min}$ and lower. Ferrite envelopes around the graphite nodules were observed to occur in the cast iron cooled at a rate equal to or lower than $20^{\circ} \mathrm{C} / \mathrm{min}$.

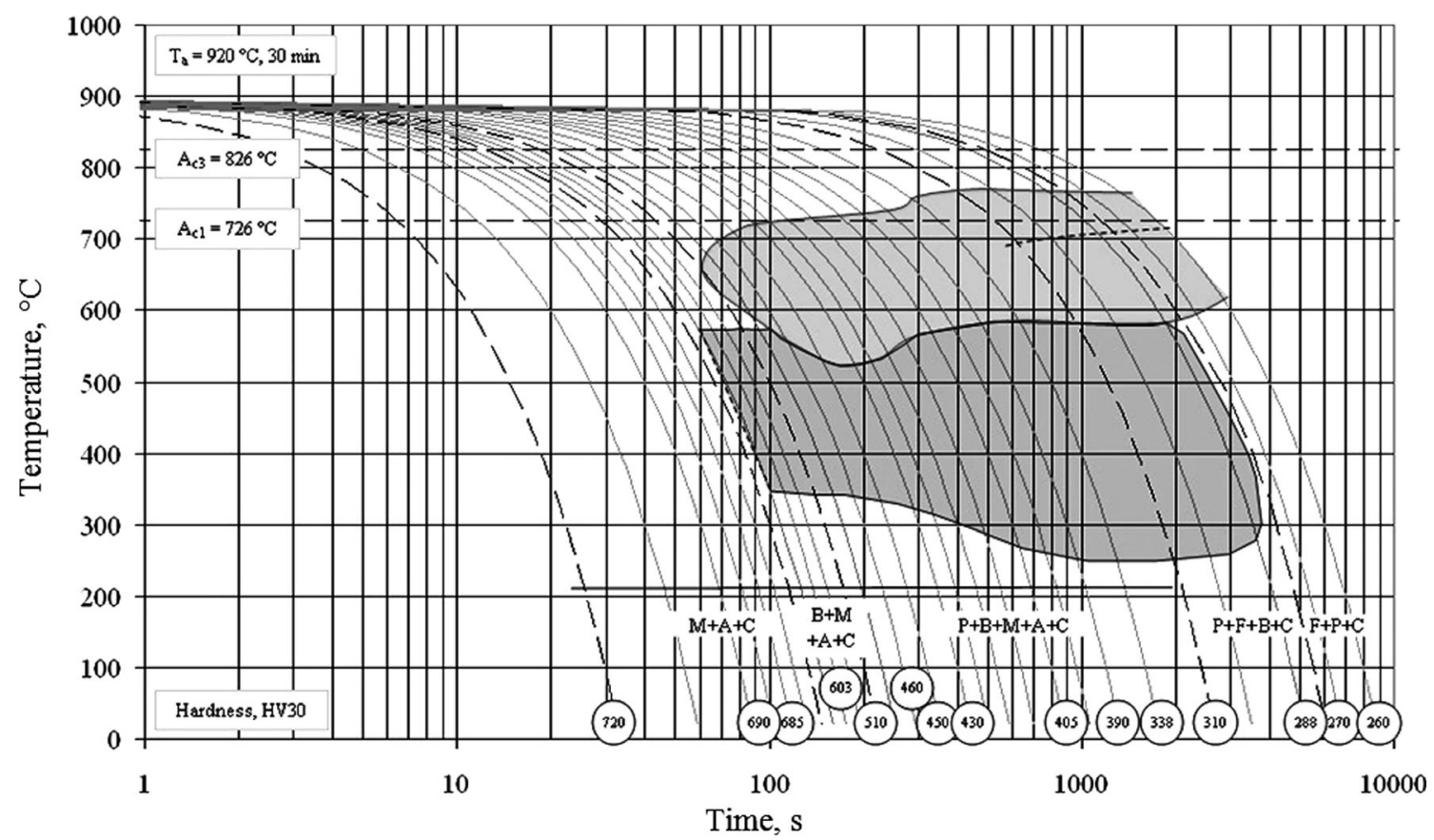

Fig. 2 The CCT curves of nodular cast iron with carbides of the following chemical composition: $3.75 \% \mathrm{C}, 2.40 \% \mathrm{Si}, 0.33 \% \mathrm{Mn}, 0.51 \% \mathrm{Cr}, 1.41 \%$ Mo, and $1.03 \%$ Cu. $F$ ferrite, $P$ pearlite, $B$ bainite, $A$ austenite, $M$ martensite, $C$ carbides 


\subsection{ADI}

One of the stages in the production of ADI is making the cast iron with nodular graphite and the addition of elements such as $\mathrm{Mn}, \mathrm{Ni}, \mathrm{Cu}, \mathrm{Mo}, \mathrm{Cr}, \mathrm{Sn}$, or other elements allowing the formation of a pearlitic or pearlitic-ferritic structure with improved hardenability. Here some attention deserves the fact that not every grade of ductile iron is suitable for the production of ADI. Some grades of low-alloy and high-alloy cast iron (e.g., high-nickel cast iron) are either not used to produce $\mathrm{ADI}$ or their use is not economically viable. The spheroidizing treatment is performed with magnesium or its respective compounds. In some cases, the rare earth elements such as, for example, $\mathrm{Ce}$ or $\mathrm{Re}$ are also used. The spheroidizing treatment of cast iron consists in the introduction of appropriate amounts of magnesium into the bath of cast iron, resulting in the precipitation of graphite with nodular morphology. The refinement and proper shape of graphite depend on the content of sulfur and magnesium that are present in the alloy in a residual form as its constituents.

Differences in mechanical properties of the specific ADI grades are associated with differences in the structure. This, in turn, is due to different variants of the applied heat treatment. Through control of the parameters such as the temperature of austenitizing or austempering, the properties of ADI can be modelled. This is best seen in the tensile strength $\left(R_{\mathrm{m}}\right)$-toelongation $(A)$ relationship. In the case of austempering, a very important parameter is the temperature of the process. If the cast iron is austempered at a temperature above $400^{\circ} \mathrm{C}$, due to rapid transformation, the presence of carbides can be expected in the structure with the resulting consequence of the cast iron having inadequate ductility. The content of austenite relative to the content of ferrite is highest in the range of 350 to $370{ }^{\circ} \mathrm{C}$, and then the cast iron has the highest elongation and the lowest strength.

Table 3 shows a number of ADI variations designated with symbols from ADI-1 to ADI-6. They represent different chemical compositions of the cast iron subjected later to the heat treatment of austenitizing and austempering. The data for tests was collected from the 23 variants of the chemical composition. The data on the ADI mechanical properties obtained by the application of different heat treatments covered 172 samples [30]. Table 4 shows only a few selected variants of this material.

A general scheme of the process for making ADI is shown in Fig. 3.

Characteristics of the set of samples are presented in Table 5.

From the results of the analysis, it follows that ADI ductility increases with the increasing content of austenite in the structure, while the yield strength $\left(R_{\mathrm{p} 0.2}\right)$ and the tensile strength $\left(R_{\mathrm{m}}\right)$ decrease. The content of austenite in the structure increases with the increasing temperature of the ausferritizing treatment; during this time the content of ferrite decreases. With the increasing temperature, the ferrite coarseness increases. The results show that at lower temperatures of the ausferritizing treatment $\left(260^{\circ} \mathrm{C}\right)$, the content of ferrite in the cast iron increases, thus leading to an increase in the yield strength $\left(R_{\mathrm{p} 0.2}\right)$ and tensile strength $\left(R_{\mathrm{m}}\right)$ for both of the examined cast iron chemical compositions (Fig. 4). Fracture toughness (the stress intensity factor) reaches its peak for the hardness value of approx. $40 \mathrm{HRC}$, that is, when the cast iron contains approx. $60 \%$ ferrite and $25 \%$ austenite. This means that the optimum values are achieved for the ausferritizing treatment carried out at a temperature of approx. $280{ }^{\circ} \mathrm{C}$ for a time of approx. $3.5 \mathrm{~h}$. The analysis of microstructure shows that the optimum fracture toughness can be achieved with a microstructure consisting of lower bainite and fine strips of ferrite and with the retained austenite in an amount of approx. $30 \%$ saturated with carbon to a level above $1.8 \%$. The optimum fracture toughness is obtained for an isothermal annealing in the range of $300-320^{\circ} \mathrm{C}[31]$.

\subsection{Preliminary data analysis—a comparison of materials}

A collective comparison of the impact of individual alloying elements on the properties of ADI and NCIC is presented on scatterplots in Fig. 5. Well visible is the drop of plastic properties caused by the majority of alloying elements. Only nickel increases the elongation of the examined materials and their strength.

Table 4 Chemical composition of different ADI variations

\begin{tabular}{lllllllllllllll}
\hline & $\mathrm{C}$ & $\mathrm{Si}$ & $\mathrm{Mn}$ & $\mathrm{Mg}$ & $\mathrm{Cu}$ & $\mathrm{Ni}$ & $\mathrm{Mo}$ & $\mathrm{S}$ & $\mathrm{P}$ & $\mathrm{V}$ & $\mathrm{Cr}$ & $\mathrm{Ti}$ & $\mathrm{Sn}$ & $\mathrm{Al}$ \\
\hline ADI-1 & 3.65 & 2.76 & 0.36 & 0.045 & 0.6 & 0.9 & - & 0.014 & 0.016 & - & - & - & - \\
ADI-2 & 3.51 & 2.45 & 0.3 & 0.036 & - & - & - & 0.01 & 0.017 & - & - & - & - \\
ADI-3 & 3.5 & 2.65 & 0.4 & 0.035 & 0.055 & 1.6 & 0.3 & 0.01 & 0.021 & 0.05 & - & 0.02 & - \\
ADI-4 & 3.5 & 2.47 & 0.38 & 0.035 & 0.35 & 1.57 & 0.3 & 0.01 & 0.021 & 0.05 & 0.5 & 0.02 & - \\
ADI-5 & 3.54 & 2.81 & 0.43 & 0.05 & 0.56 & 1.52 & 0.3 & 0.009 & 0.031 & - & 0.3 & - & - & - \\
ADI-6 & 3.4 & 2.69 & 0.19 & 0.044 & 0.87 & 0.73 & 0.23 & 0.01 & 0.02 & - & 0.04 & 0.004 & 0.007 & 0.015 \\
\hline
\end{tabular}


Fig. 3 A general scheme of the process for making ADI

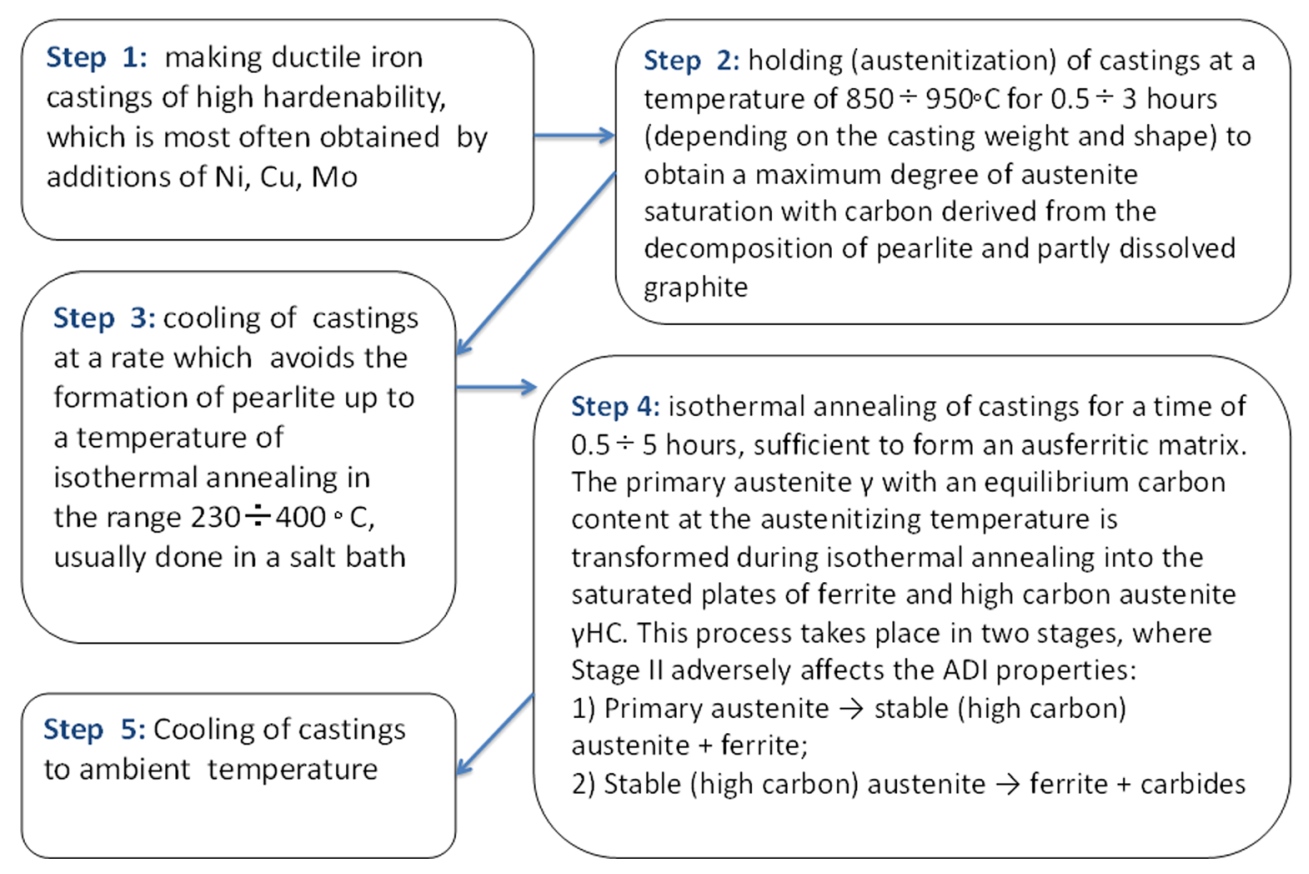

The conclusions from the comparison of properties are as follows: (1) The ductile iron with upper bainite shows nearly two times higher resistance to abrasive wear than its pearlitic counterpart; in ADI, this increase is nearly three times higher. (2) The highest abrasive wear resistance was found in the ductile iron with a mixture of upper and lower bainite. Its loss of weight amounted to approx. $64 \%$ of the weight loss suffered by ADI. (3) Compared to all other types of bainitic nodular cast iron, ADI shows the highest wear rate in parts mate with hardened steel. (4) The conducted studies of the wear resistance have proved that the developed nodular cast iron with carbides can successfully be used for machine parts which should offer high resistance to wear, thus replacing, e.g., castings made of ADI. (5) The NCIC has lower strength than ADI but its elongation is comprised in the same range of values as ADI (Fig. 6a). (6) Compared with other materials (cast steel, some grades of steel, grey cast iron, and ductile iron), ADI and NCIC have a lower elongation but higher strength and hardness. Clear division into subgroups based on the hardness values is also observed in the ADI itself (Fig. 7). One of the subgroups has a hardness at the level of NCIC, and the other shows definitely higher values. (7) It can be stated that NCIC has properties similar to ADI, adopting the values intermediate between the ADI and other construction materials, mainly as regards the strength, hardness, and elongation (Fig. 6b). This is confirmed by the canonical
Table 5 Characteristics of the set of ADI samples

\begin{tabular}{|c|c|c|c|c|c|}
\hline \multicolumn{6}{|c|}{ Chemical composition } \\
\hline $\mathrm{C}$ & $\mathrm{Si}$ & $\mathrm{Mn}$ & $\mathrm{Mg}$ & $\mathrm{Cu}$ & $\mathrm{Ni}$ \\
\hline $3.56-3.62 \%$ & $2.45-2.63$ & $0.12-0.32 \%$ & $0.037-0.065 \%$ & $0.44-0.93 \%$ & $0.43-1.9 \%$ \\
\hline \multicolumn{6}{|l|}{ Heat treatment } \\
\hline \multicolumn{3}{|l|}{ Austenitizing } & \multicolumn{3}{|l|}{ Ausferritizing } \\
\hline \multicolumn{2}{|l|}{ Temperature } & Time & Temperature & \multicolumn{2}{|c|}{ Time } \\
\hline $900{ }^{\circ} \mathrm{C}$ & & $90-120 \mathrm{~min}$ & $300-360^{\circ} \mathrm{C}$ & \multicolumn{2}{|c|}{$120-180 \mathrm{~min}$} \\
\hline \multicolumn{6}{|c|}{ Mechanical properties } \\
\hline \multicolumn{2}{|l|}{ Tensile strength } & Yield strength & Elongation & \multicolumn{2}{|c|}{ Hardness } \\
\hline \multicolumn{2}{|l|}{$862-1602 \mathrm{MPa}$} & $455-1418 \mathrm{MPa}$ & $0.3-20 \%$ & \multicolumn{2}{|c|}{$233-629$} \\
\hline
\end{tabular}



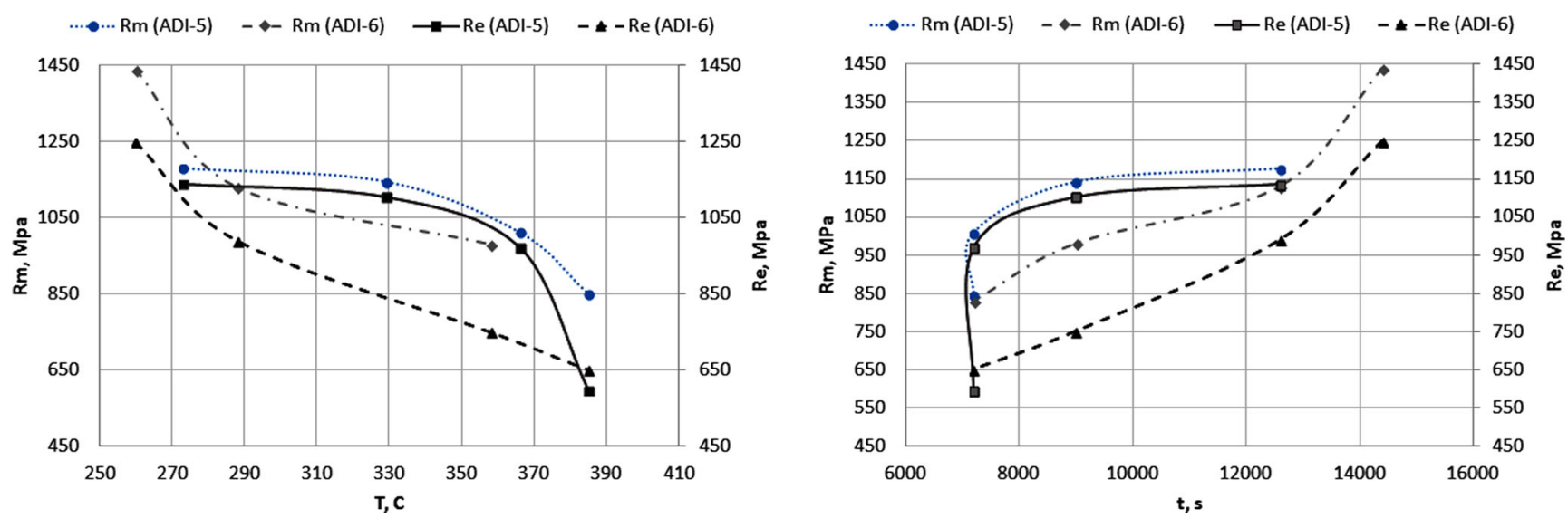

Fig. 4 Example of relationship between the tensile strength and temperature and time of the isothermal annealing

analysis of the impact of mechanical properties on the division of materials into groups (ADI, NCIC, and others) and is the basis for drawing some conclusions, where component 1 comprises mainly the strength and component 2 the elongation and hardness.

\section{Methods of data mining-machine learning}

Machine learning methods, derived from research on artificial intelligence, allow generating knowledge in the form of models or rules from a set of training data for the future use of this knowledge in the analysis of new facilities. Artificial intelligence methods have already been used in various problems of the engineering and industrial nature, as evidenced by the rich literature in this area. The collection of these machine learning methods includes the most popular tools for classification, such as minimum distance classifiers (k-nearest neighbors $(\mathrm{kNN})$ ), induction of decision trees, artificial neural networks, and also the most modern tools, like support vector machine (SVM).
Fig. 5 Analysis of the impact of various alloying elements on the properties of ADI and NCIC
$\mathrm{Cu}$

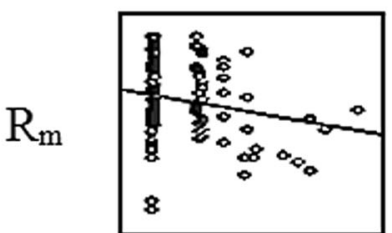

A

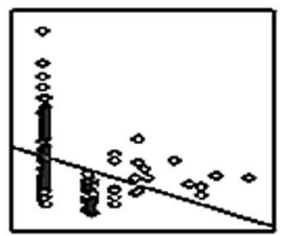

HB
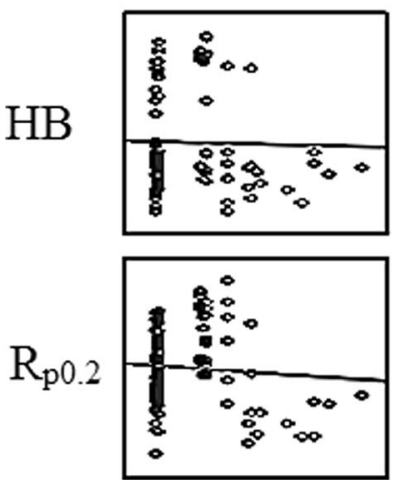

$\mathrm{Ni}$
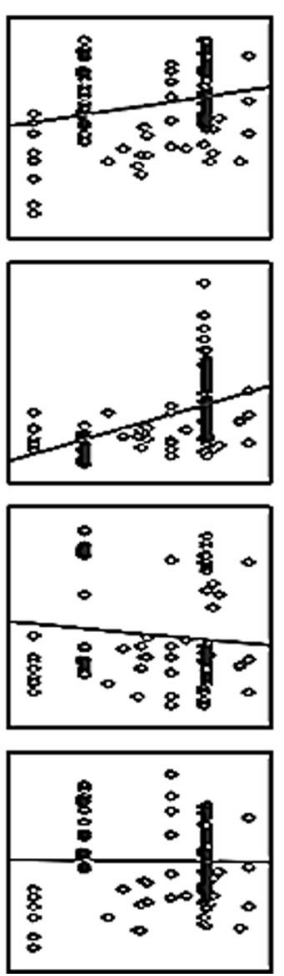

Mo
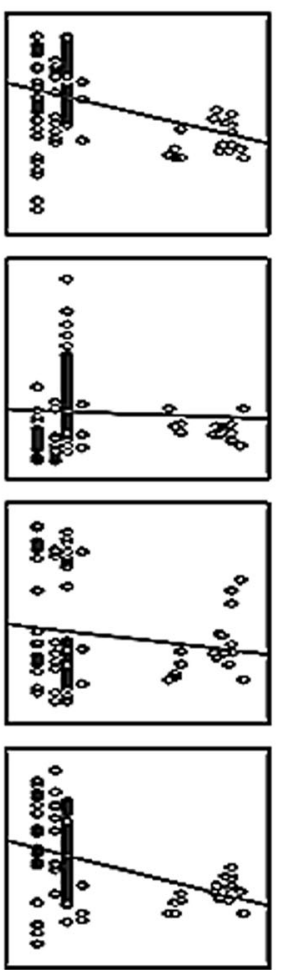

$\mathrm{Cr}$
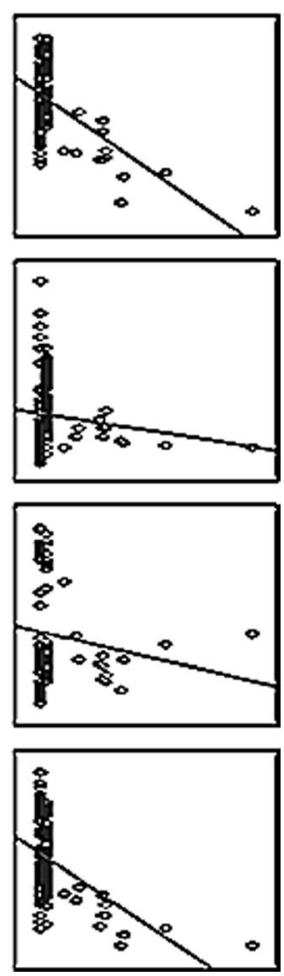
a

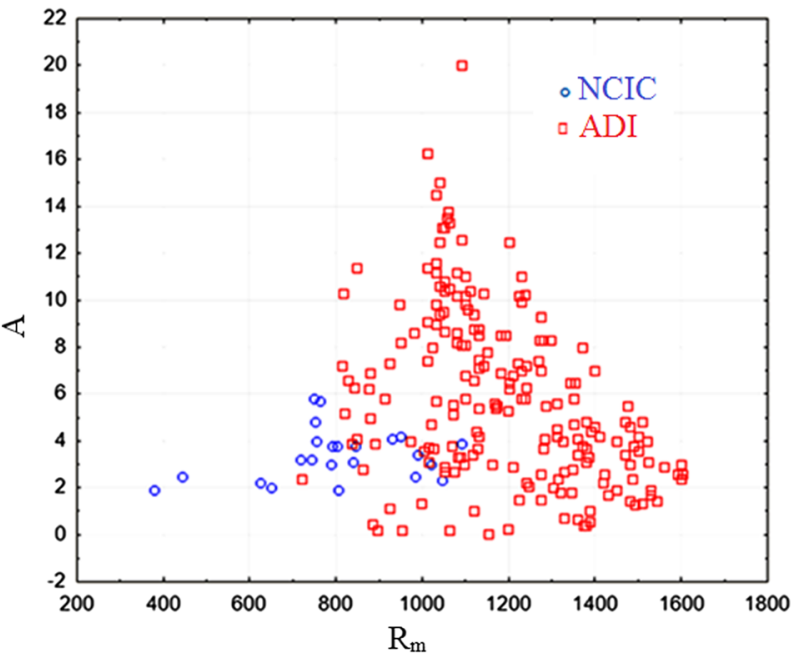

b

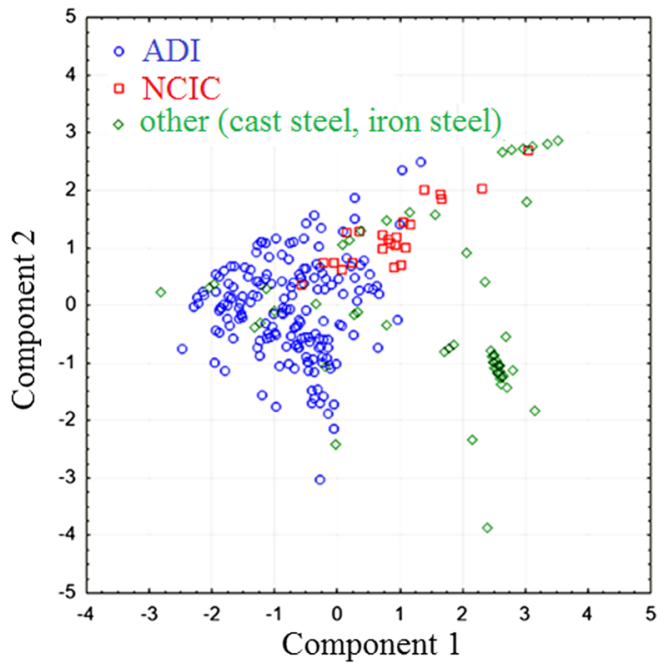

Fig. 6 a Tensile strength and elongation compared for NCIC and ADI. b Canonical analysis of the impact of $R_{\mathrm{m}}, R_{\mathrm{p} 0.2}, \mathrm{HB}$, and $A_{5}$ on the division into three groups of materials

\subsection{Machine learning using kNN, CART, CHAID, and ANN classifiers}

In all these algorithms, learning proceeds according to a certain pattern: on the basis of training data (approx. $70 \%$ of cases), a classification model is constructed. This model can take a variety of forms: a set of rules, the distance matrix, weights on connections, or vectors and matrices. The model is tested during learning process with approx. $15 \%$ of cases, and its final form is validated (subject to verification) using the last discriminated group of data-approx. $15 \%$. The evaluation of the model can be performed with the use of a few parameters. Three of them, i.e., the quality of learning, testing, and validation, indicate the percentage of cases that are correctly classified during each phase of the model building. The final performance of the model can be tested for the compatibility of results with the dependent variable input data. In this study, parameters such as the value of test $\chi^{2}$ (chi-squared) or

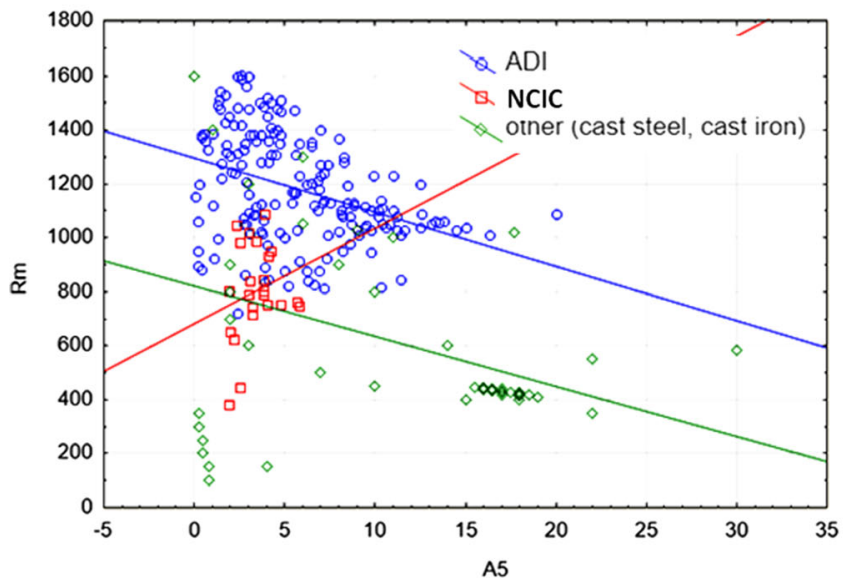

Fig. 7 Properties in groups of materials
$G^{2}$ ( $G$ test) could be pointed out as compliance tests (the goodness-of-fit). Those tests are statistical methods of validation of goodness of fit to a distribution and for independence in contingency tables and also used to compare the goodness of fit of two models. Another criterion could be the percentage incompatibility that determines model misclassification for the same set of input data and the dependent variable.

The following chapters describe research involving the construction of 18 models using various methods of machine learning and comparing the results to choose the best classification tool for the disclosed problem of casting material selection according to preset mechanical properties.

For this purpose, the kNN classifier was used. This method uses a matrix of distances between each of the elements in the training set. Classification is based on a comparison of selected (nearest) neighbors of the new object. Neighborhood is determined based on the distance, which is the Euclidean distance, or other metrics. $K$ parameter determines the amount of

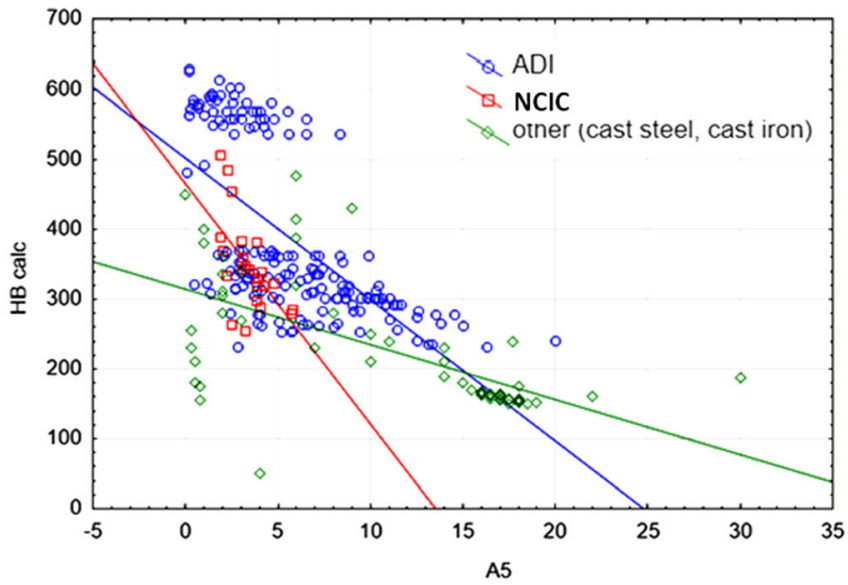


neighbors. It bases on a set of training cases and does not perform the training process, but when the classification of a new case is called, it looks in the matrix for distances $k$ of the nearest neighbors. Most of the values of the dependent variables among the $k$-neighbors are the values of the classifier decisions. In other words, the largest class among the $k$-neighbors becomes the classifier response. This method has been known for years and its greatest advantage is the simplicity, intuitiveness, and no need to build a "fixed" model - the algorithm can be based on dynamically changing data, and thus the process of "training" is most flexible.

The second applied algorithm is called artificial neural networks (ANN). It is a very popular method in the current research on machine learning, successfully used in the control of devices and optimization of processes in the industry. These models allow with the aid of training data the modification of weights on the connections in a network of neurons, which are the computing cells. Here, the training process consists in optimizing the matrix weights, which results in the best representation of the training signal sequence. This method is efficient and effective for most problems but has one major drawback - the resulting model cannot be easily understood by a human. The model does not generate rules or equations that the user could interpret or verify based on his own domain knowledge [32, 33].

Induction algorithms of classification and regression trees (CART) and chi-square automatic interaction detection (CHAID) were used, where the idea was to proceed with the division of a data set into subsets until each subset contains objects belonging to only one class of the dependent variable. The division was made basing on various tests - Gini index for the CART algorithm or $\chi^{2}$ test for the CHAID algorithm. These methods allow the construction of decision rules based on the explanatory (independent) variables. Decision trees are a graphical representation of the rules disclosed in a userfriendly form. These algorithms make it possible not only to create rules but also to quantify the importance of each variable in the model, which is sometimes as important as the model itself. The variable is defined as important in the classification process, i.e., providing information on classes, when it shows appropriate degree of readiness to participate in the division of the dependent variable that is measured during the construction of the tree. The determined validity enables creating a ranking of independent variables in terms of their impact on the dependent variable. The validity is the degree of covariance with the dependent variable. Some obvious advantages of classifiers based on trees are as follows: (1) their graphical representation, which is clear, easily interpreted, and verifiable on the basis of domain knowledge; (2) the ability to determine the validity of the predictors; (3) insensitivity to noise and outliers; (4) the possibility of action based on variables both quantitative and qualitative; and (5) the outcome in the form of a set of rules that can be used in other applications. These methods are, however, not as effective as neural networks and support vector machine. They do not achieve so good results mainly due to the discretization of quantitative variables, which demand forced generalization $[34,35]$.

The last in a group of the applied techniques is the already mentioned SVM. It is a method that determines to which of the two classes should belong a given set of input data. The task is accomplished through the designation of the widest possible boundary between classes basing on training data. This is a linear, binary, and non-probabilistic classifier. Linear classifier means that the boundary of classification is a linear function. SVM is non-probabilistic because the classification is strict, determined by the vectors, not based on the statistical analysis. Binary means that the possible result of classification is 0 or 1 . Of course, this does not mean that it is not suitable for predicting the dependent variables, which can assume more than two values, or for solving the nonlinear problems. In situations when there are more than two classes, the multiclass support vector machine may use two solutions: (1) one-versus-all, when it is building a cascade structure of binary classifiers, and (2) one-versus-one when it is forming a matrix of binary classifiers for all possible pairs of the values of the dependent variable. The result of classification in one-versus-one solution is the label of this class, which has been selected most frequently by the binary classifiers. Support vector method, although relatively young, has already found a number of practical applications, like [36-41].

In this article, special attention was paid to the algorithm which gave the best results, and it was the aforementioned support vector machine. It also deserves attention for the mere fact that being the "youngest" of all the presented techniques, it has already been included into a still relatively little known branch of machine learning.

\subsection{Support vector machine algorithm}

As has already been mentioned, the SVM classifier is a linear classifier, which does not mean that it is not capable of "handling" the problems of a non-linear nature. In this case, linear means that in every point of classification boundary, the classification is based on linear function (vectors), but as the whole problem, the boundary does not have to be a straight line. Although conventional tools, such as a linear discriminant analysis (LDA), are seeking linear discriminant functions in a space of the characteristics of the training variables, it is the SVM model which is the normal vector and a linear combination of support vectors, i.e., the nearest ones to the division border.

A solution to the problem of non-linearity (when the vectors in the training set are not linearly separable) is the socalled kernel trick-mapping the training vectors to a space of 
larger dimension, where their linear separability can be expected. The calculations are carried out using kernel functions.

The method consists in finding a border (hyperplane) that will separate the classes in a possibly acceptable manner. The system is additionally enriched with the introduced slack variable $\left(\xi_{i}\right)$, which is a penalty for points located on the wrong side of the border. The model is also defined by a parameter $C$ deciding about the size of the margin [32].

The hyperplane can be represented as $w \cdot x-b=0$, where $w$ is the vector normal to the hyperplane, $\frac{b}{\|w\|}$ parameter determines the offset of the hyperplane from the center to the coordinate system, and $\|\cdot\|$ is the Euclidean norm in the space $\mathfrak{R}^{n}$. The search for SVM model is reduced to the optimization problem, the essence of which consists in minimizing the Lagrange functional, $\|w\|, b$, and $\xi_{i}$, and maximizing the multipliers $\alpha_{i}$ and $\mu_{i}$.

$L \equiv \frac{1}{2}\|w\|^{2}+C \sum_{i=1}^{n} \xi_{i}-\sum_{i=1}^{n} \alpha_{i}\left[y_{i}\left(x_{i} \cdot w+b\right)-1+\xi_{i}\right]-\sum_{i=1}^{n} \mu_{i} \xi_{i}$

\section{The results of machine learning}

The machine learning process has been divided into two scenarios. (1) In the first scenario, raw material data should help to build a classifier most competent in identifying the material of the required mechanical properties. (2) The second variant of the analysis includes a pretreatment of data done with the method of clustering to form groups (clusters) of materials with similar properties, building next a classifier that will be capable of identifying clusters of materials with the selected features.

\subsection{Comparison of classification algorithms}

In the case under discussion, the input vectors, based on which the classification of the material is done, are composed of four dimensions: tensile strength $\left(R_{\mathrm{m}}\right)$, the force needed to break the material sample; yield strength $\left(R_{\mathrm{p} 0.2}\right)$, the stress a material can withstand without permanent deformation; hardness in Brinell scale $(\mathrm{HB})$, and elongation $\left(A_{5}\right)$. Based on data that includes 264 samples of materials with different properties - 264 vectors corresponding to the samples are available — most data relate to test materials. Based on material standards, the grades (symbols) of those materials were defined for the specified chemical compositions. Some of the samples may represent the same material, although their properties will vary within a wide range of values. These differences result from the different scenarios of the heat treatment or inoculation and are the largest obstacle to a correct and unambiguous classification. There are many vectors which have very similar properties, although they have different class labels; in other words, different materials can have very similar properties. In contrast, there are materials called by the same name, e.g., ADI-23, but after different variants of the treatment acquire different properties.

The following algorithms were used: $\mathrm{ANN}, \mathrm{kNN}$, the trees (CART:Gini, CART:G-square, CHAID) (presented in Section 3.1), and SVM. Some of them were used with various configurations of the parameters. Altogether, 18 models were made, of which SVM proved to be the best fit. The results are shown in Table 6. Neural networks (ANN) were considered in several versions. The best structures are given in the table. The best has proved to be a multi-layer perceptron (MLP) with activation function: linear and tanh. Radial networks (RBF) did not yield so good results.

The $\mathrm{kNN}$ algorithm used $v$-cross-validation to determine the best value of $k$. $K$ value determines a number of neighbors that are taken under consideration during classification process. Neighbors are the nearest object in the training set. Each neighbor is classified - it takes a label of known classes. The result of the classification takes a class that dominates the neighborhood.

Classification trees were built basing on CART algorithm using in the first case the Gini index as a criterion for division, and $G^{2}$ ( $G$-squared test) in the second case. The CHAID tree has retained the default parameters. Induction of the classification trees (as it was mentioned earlier) bases on the division of the training data. Based on the sequence of test on the input variables $\left(R_{\mathrm{m}}, R_{\mathrm{p} 0.2}, \mathrm{HB}, A_{5}\right)$, the algorithm seeks to create

Table 6 Comparison of classification results using ANN, kNN, CART, CHAID, and SVM

\begin{tabular}{llllllllllllllll}
\hline Symbols & ANN & & kNN & CART & & CHAID & SVM & & & & \\
\hline Fitness & MLP & MLP & k-4 & Gini & G2 & Chi2 & Line & RBF & RBF & RBF & RBF & RBF & RBF \\
& $4-4-40$ & $4-8-40$ & & & & & & $C=7$ & $C=5$ & $C=8$ & $C=9$ & $C=10$ & $C=12$ & $C=15$ \\
& & & & & & & & & $\gamma=3$ & $\gamma=5$ & $\gamma=0.25$ & $\gamma=3$ & $\gamma=5$ & $\gamma=2$ \\
$\chi^{2}$ & 17.8 & 9.2 & 22.3 & 0.5 & 3.7 & 0.1 & 0.3 & 8.2 & 9.9 & 0.1 & 8.1 & 9.2 & 7.1 \\
$G^{2}$ & 43.8 & 35.3 & 32.5 & 6.5 & 17.0 & 2.1 & 4.3 & 24.0 & 29.4 & 2.1 & 23.9 & 26.8 & 21.1 \\
Incompatibility [\%] & 13.8 & 16.6 & 48.0 & 44.2 & 50.5 & 73.7 & 56.0 & 46.0 & 40.0 & 56.0 & 38.0 & 42.0 & 34.0 \\
Learning [\%] & 86.2 & 83.4 & - & 34.5 & 31.6 & 46.4 & 56.1 & 76.7 & 87.7 & 53.5 & 86.4 & 90.9 & 85.1 \\
Testing [\%] & 63.3 & 66.7 & - & - & - & - & 44 & 54 & 60 & 44.0 & 62 & 58 & 66.0 \\
Validation [\%] & 60.0 & 63.3 & 41.2 & 50.7 & 52.1 & 52.1 & 53.1 & 71.2 & 80.9 & 51.0 & 80.4 & 82.9 & 80.4 \\
\hline
\end{tabular}




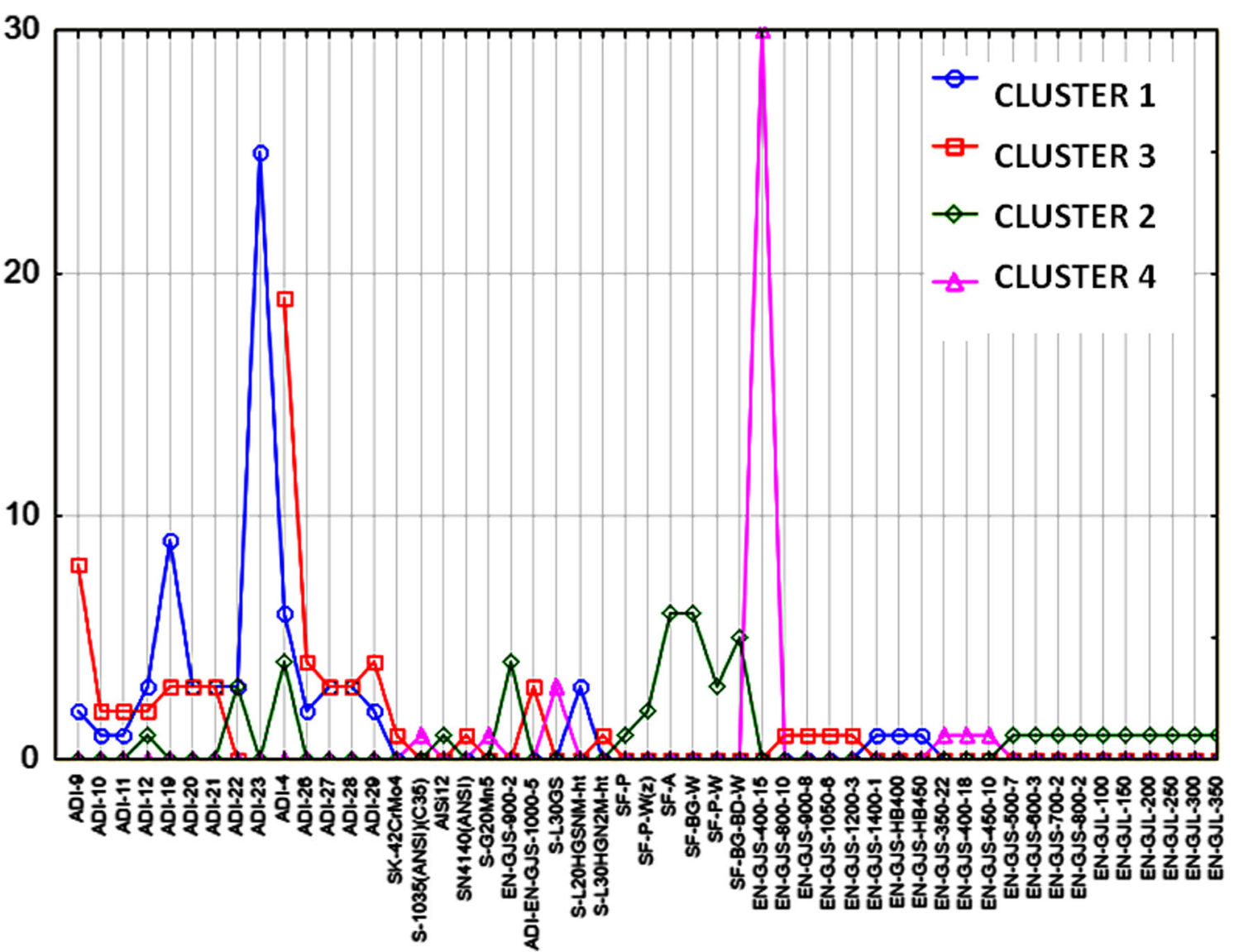

Fig. 8 Assignment of materials to clusters based on the properties such as $R_{\mathrm{m}}, R_{\mathrm{p} 0.2}, \mathrm{HB}$, and $A_{5}$ using a cluster analysis algorithm EM

homogeneous classes of dependent variable. Inpurity - measure specifying the number of cases outside the class - can be measured with various metrics: Gini index, $G^{2}$, or $\chi^{2}$ test. None of these algorithms have yielded sufficiently interesting results.

Artificial neural networks are the structures of simple mathematical elements designed for the signal processing. ANN-automatic artificial neural network - is the algorithm of developing neural networks with various parameters as number of neurons, number of layers, and activation functions. The algorithm creates number of structures which are learned, tested, and validated and in turn returns the best architectures of networks - architectures that return the result the most similar to that expected.

The first and second rows of the Table 6 determine the parameters of the models. Subsequent rows of the table include various parameters for an assessment of the models

Table 7 The table of cardinality values for clusters obtained with EM algorithm

\begin{tabular}{lll}
\hline Cluster & No & Percent \\
\hline 1 & 72 & 27.27 \\
3 & 108 & 40.91 \\
2 & 46 & 17.42 \\
4 & 38 & 14.39 \\
Total & 264 & 100 \\
\hline
\end{tabular}

described in Section 3.1. It may be noted that the algorithms of $\mathrm{kNN}$ and of the decision trees induction (CART and CHAID) definitely fail to yield good results in this particular case - their quality in validation group is only $50 \%$.

The best results were achieved with the neural networks and SVM. Neural networks show particularly good performance in fitting the test results to the dependent variable in the input data, which means that the algorithm has a high capability of the reference sequence replication. Poor results of validation, i.e., verification based on the data which do not participate in the network training process, point to the network tendency to "overtraining" and a weakness in the generalization of models.

In this aspect, the best performance offered the SVM algorithm. In spite of a high percent non-compliance rate for most of the cases, in validation test, it achieved the maximum values of up to $80 \%$. This means the greatest ability to generalize patterns and gives the best chance for correct operation in the case of new samples not included in the training data.

However, none of the algorithms have proved to be faultless, and as regards some of the assessments, it could even be said that the results were unsatisfactory, to mention as an example the quality of testing. This means that the classification gives only approximate results, and thus the decision which 

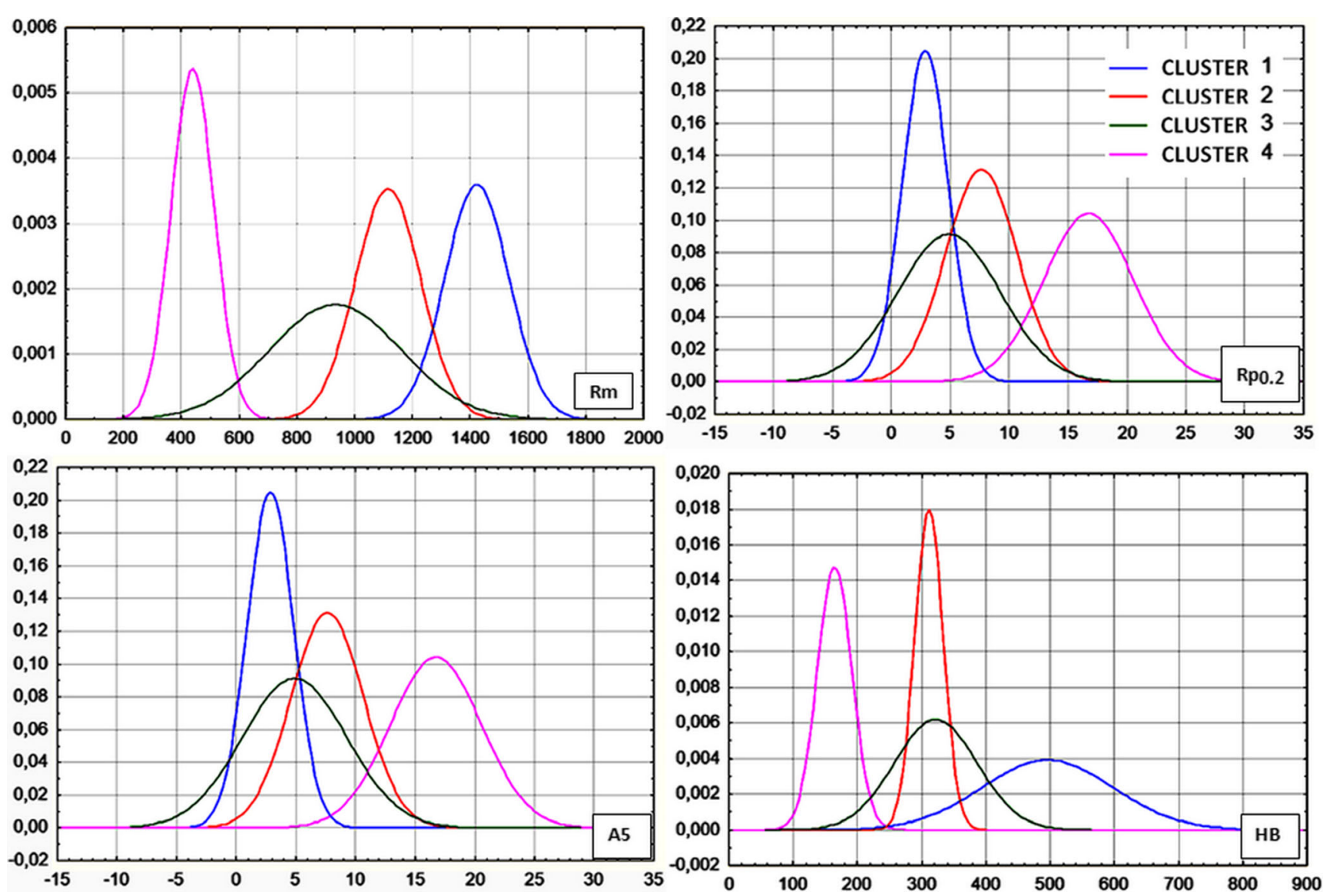

Fig. 9 The distributions of variables in individual clusters

material has the properties specified by the user can not be fully automatic. Consequently, the choice of construction material still requires some amount of domain knowledge. This formulation of preliminary conclusions allowed introducing some modifications to the currently adopted problem embodiment.

\subsection{Supporting classification analysis: clustering}

As stated in the previous section, the classification according to material symbols is not fully effective and cannot be the sole criterion for the choice of material. In fact, industrial users may be satisfied with the support at the level of material group selection - this meaning an answer to the question whether to choose cast iron, or cast steel, or steel, etc. Basing on these assumptions, an additional, intermediate process of the data analysis has been proposed. It is called the cluster analysis.

The raw data in the form such as described in Section 4.1 was subjected to a pretreatment in the form of cluster analysis done by the expectation maximization (EM) method. The algorithm described in detail in [33] allows grouping of objects into clusters based on the values of the characteristics describing these objects (variables) using two-criteria optimization: minimizing the distance within the cluster and maximizing the inter-cluster distances (Fig. 8). It is a probabilistic algorithm - instead of assigning definitely an example to a group, it estimates the probability of such affiliations. The calculation of the affiliation takes into account the distribution characteristics. The method comprises two steps carried out alternately until between successive runs there is no noticeable improvement: (1) estimation (expectation). For the currently estimated distribution parameters of the examples, it allocates to the examples the probability of belonging to a group. (2) Maximization: Changing the current distribution parameters for such that will lead to a model more in line with the data (the distribution of examples). For this purpose, it uses the probability of membership in various groups determined in step 1.

Analyzing the resulting clustering, it can be concluded that clusters 1 and 3 are mainly materials from the family of ADI. Cluster 2 is mainly NCIC and some individual cases of ADI, as well as certain types of nodular cast iron with high $R_{\mathrm{m}}$. Cluster 4 groups include other materials-nodular cast iron with lower $R_{\mathrm{m}}$, ferritic ductile iron, and steel. These results 



Fig. 10 Two-dimensional comparison of the values of features for clustering

confirm previous analyses described in Section 2.3. The cardinality values for clusters are presented in Table 7.

Individual clusters have different distributions of the values of the input variables, which in this case are the mechanical properties. It can be seen (Fig. 9) that the cluster grouping NCIC and the most similar ADI, that is cluster 2, have lower strength than cluster 1 (ADI), lower ductility, and hardness but higher elongation. At the same time, in many areas, it coincides with a group of materials from the ADI family (cluster 3 ). What is important is the fact that nearly no area of the properties coincides with cluster 4 , that is, with other materials. So, it can be concluded that some of the materials from the NCIC family are very similar to the ADI subset and as such are substitutable (Fig. 10).

\subsection{Classification using cluster analysis results}

The results of cluster analysis allow re-considering the problem of classification. Each material has been assigned to one of four clusters created according to the division by mechanical properties. As a result, the problem of classification will consist in indicating a group of similar materials and not an individual material as has been done previously (see Section 4.1.). In this way, an error is avoided which results from the overlapping properties of materials and a bias associated with variations in the properties of different samples of the same class of materials. As the analysis using a CART algorithm shows, for thus processed data, the results are very promising (Fig. 11a).

Even the CART algorithm, which in previous studies did not give good results, now allows for very efficient classification and drawing of further conclusions. An important role in this classification will play the variables such as the tensile strength $\left(R_{\mathrm{m}}\right)$ and the yield strength $\left(R_{\mathrm{p} 0.2}\right)$, but rough division can be done using hardness (HB) only (Fig. 11b).

As has been indicated previously, the induction of classification trees allows discovering the relationships which enable the division of partitions (SVM allows insight into the support 

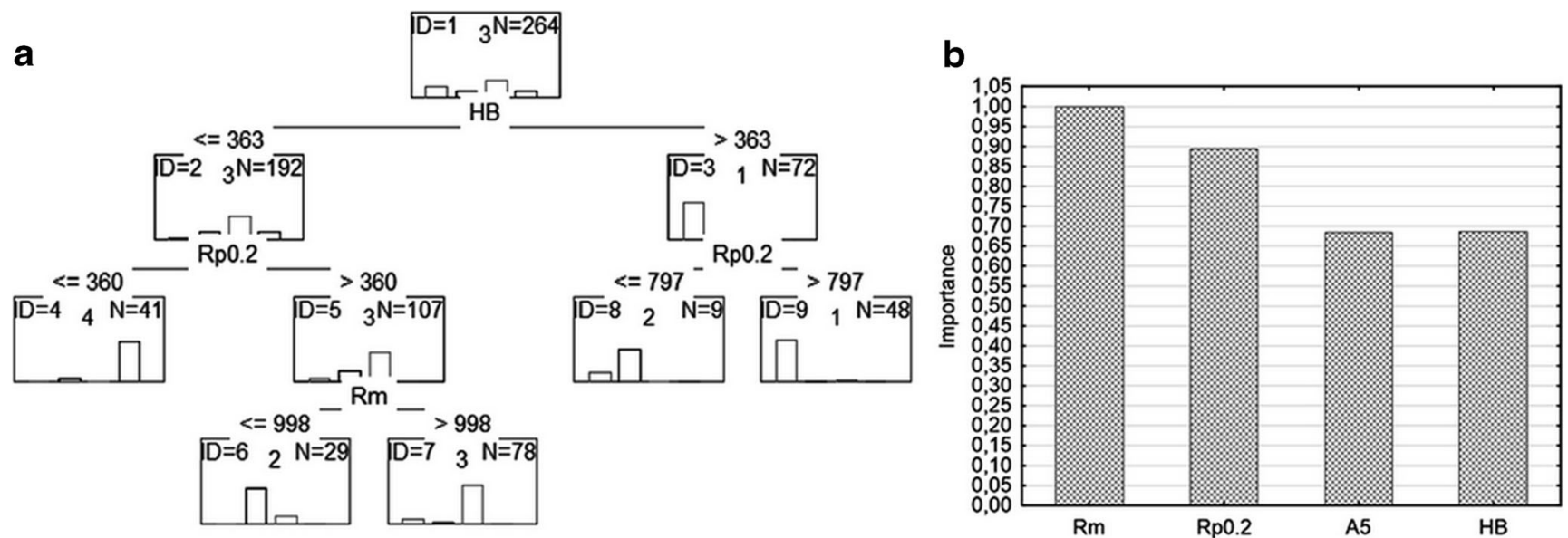

Fig. 11 a The CART tree for data preceded by cluster analysis. b The importance of predictors

vectors that are not easily understood by the user). Visualizations shown in Fig. 10a allow for the model evaluation by a domain expert. The successive bars in each of the tree nodes reflect the percent content of objects from each cluster in a partition represented by the node. If the leaf bears only one bar, it means a homogeneous class and inerrancy of the rule (represented by the entire branch). It can therefore be read from a tree that, e.g., the low hardness and low yield strength of the material mean the material from group 4, that is, cast steel, ductile iron, and some grades of steel, and this can be said with the confidence equal to $93 \%$. If hardness exceeds $363 \mathrm{HB}$ and the yield strength is higher than $797 \mathrm{MPa}$, it means cluster 1, that is, ADI (98\% confidence). The most significant errors of the trees are also visible. The classification matrix indicates where there is a risk of making a mistake - cluster 2 is the one most commonly confused with materials from clusters 1 and 3, which means that there are ADI types with very similar properties to the NCIC cast iron.

General quality parameters of CART trees are shown in Table 8 and are compared with other algorithms.

It turns out that the initial clustering allows in further step an error-free classification of the materials. The best results of validation were obtained for the neural networks, but all the used algorithms, even decision trees, have gained an over $95 \%$ quality, which represents a huge improvement, with the CART algorithm having a particularly high sequence fit in the similarity test $G^{2}$. After the introduction of cluster analysis done with EM algorithm, the classification quality has approached $100 \%$, which means that clustering enables an error-free classification only in the situation where the user does not want to find a particular material but one of the four material groups.

\section{Summary}

The article presents the results of experimental studies of materials and is enriched with the data analysis aimed to classify these materials according to the specified mechanical properties. The advantages of modern casting materials, such as ADI and NCIC, were presented.

To present these materials to the potential users and make them more popular, models based on machine learning techniques were built. Their task is to support the selection of construction materials at the stage of product design. The models are based on the training data sets
Table 8 The results of classification based on cluster analysis - comparison of algorithms

\begin{tabular}{lllllll}
\hline Clusters & CART & SVM & & \multicolumn{3}{c}{ ANN } \\
\hline Fitness & Gini Index & Line & RBF & RBF & MLP & MLP \\
& & $C=8$ & $C=10$ & $C=10$ & $4-3-4$ & $4-8-4$ \\
& & & $\gamma=0.25$ & $\gamma=3$ & & \\
$\chi^{2}$ & 3.1 & 0.57 & 0.57 & 0.21 & 0.06 & 0.12 \\
$G^{2}$ & 42.9 & 6.53 & 6.53 & 4.20 & 4.06 & 6.12 \\
Incompatibility [\%] & 9.8 & 6.00 & 6.00 & 1.38 & 1.38 & 2.07 \\
Learning [\%] & $97.9 \%$ & 97.4 & 97.4 & 98.7 & 98.6 & 97.9 \\
Testing [\%] & - & 94 & 94 & 100 & 100.0 & 100.0 \\
Validation [\%] & $97.6 \%$ & 96.5 & 96.5 & 99.02 & 100.0 & 100.0 \\
\hline
\end{tabular}


obtained from experimental studies carried out on the samples of materials and from the norms and standards concerning other materials, such as cast steel, grey cast iron, ductile iron, etc.

In the training process, 18 models with different parameters using different algorithms were built but all failed to give the satisfactory results of classification; only the cluster analysis allowed re-training of models and achieving nearly faultless classification of the groups of materials with similar properties.

Thus, constructed methodology of comparative analysis also provides a convenient exploratory path for analyses expanded with the new content of materials either taken from the groups listed here or entirely new like bronzes or aluminum alloys, whose structural characteristics can be combined and used as a range of options by the technologist or designer.

The proposed methodology indicates the similarities between materials and allows combining various materials in clusters. Errors in the algorithm classification also emphasize the subtlety of the differences in material properties in particular groups, to mention as an example the austenitic ductile iron and ADI- 6 with the chemical composition as given in Table 3.

The developed method of comparative analysis cannot be the sole criterion for the selection of material, due to the mere fact that it takes into account only the characteristics selected for analysis, disregarding other material properties, e.g., wear resistance or density. However, this is due to a small number of the experimental data and not to the limitations imposed by the algorithms. The methods shown in the article can be successfully applied to more complex input vectors and thus can be used in applications capable of supporting not only the rough decisions or offers made to customers in production plants but also the detailed process of product design done by the technologist.

Acknowledgments Financial support of The National Centre for Research and Development LIDER/028/593/L-4/12/NCBR/2013 is gratefully acknowledged.

Open Access This article is distributed under the terms of the Creative Commons Attribution 4.0 International License (http:// creativecommons.org/licenses/by/4.0/), which permits unrestricted use, distribution, and reproduction in any medium, provided you give appropriate credit to the original author(s) and the source, provide a link to the Creative Commons license, and indicate if changes were made.

\section{References}

1. Daber S, Prasad R (2008) Influence of austenitising temperature on the formation of strain induced martensite in austempered ductile iron. J Mater Sci 43:4929-4937

2. Olson BN, Moore DJ, Rundman KB (2002) Potential for practical applications of ausforming austempered ductile iron. AFS Transactions 111:965
3. Putatunda SK (2001) Development of austempered ductile cast iron (ADI) with simultaneous high yield strength and fracture toughness by a novel two-step austempering process. Mater Sci Eng A 315: $70-80$

4. Bayati H, Elliot R (1999) The concept of an austempered heat treatment processing window. Int J Cast Metals Res 11:413-417

5. Skoczylas P, Krzyńska A, Kaczorowski M (2011) The comparative studies of ADI versus Hadfield cast steel wear resistance. Arch Foundry Eng 11:123-126

6. Tybulczuk J, Kowalski A (2003) ADI. The properties and application in industry. Castings atlas. Instytut Odlewnictwa, Kraków (in Polish)

7. Keough JR (2010) Austempered ductile iron (ADI) - a green alternative. American Foundry Society, USA

8. Pietrowski S, Gumienny G (2010) Bainite obtaining in cast iron with carbides castings. Arch Foundry Eng 10:109-114

9. Gumienny G (2010) Bainitic-martensitic nodular cast iron with carbides. Arch Foundry Eng 10:63-68

10. Gumienny G (2010) Chromium and copper influence on the nodular cast iron with carbides microstructure. Arch Foundry Eng 10: $47-54$

11. Gumienny G (2012) The effect of nodular cast iron metal matrix on the wear resistance. Arch Foundry Eng 12:179-186

12. Pietrowski S, Gumienny G (2012) Microsegregation in nodular cast iron with carbides. Arch Foundry Eng 12:127-134

13. Gumienny G (2013) Carbidic bainitic and ausferritic ductile cast iron. Arch Metall Mater 58:1053-1058

14. Gumienny G, Klimek L (2014) Effect of temperature on ausferritic nodular cast iron microstructure. Arch Foundry Eng 14:21-24

15. Regulski K, Szeliga D, Kusiak J (2014) Data exploration approach versus sensitivity analysis for optimization of metal forming processes. Key Eng Mater 611-612:1390-1395

16. Regulski K et al. (2012) Data exploration approach in control of metal forming manufacturing chain: example of fasteners production. Steel Research International spec. ed: 611-612:1319-1322

17. Kluska-Nawarecka S, Wilk-Kołodziejczyk D., Regulski K et al (2011) Rough sets applied to the RoughCast system for steel castings. In: Nguyen NT et al. (ed) Intelligent information and database systemsof the series Lecture Notes in Computer Science, Berlin; Heidelberg: Springer-Verlag 6592:52-61

18. Nawarecki E, Kluska-Nawarecka S, Regulski K (2012) Multiaspect character of the man-computer relationship in a diagnosticadvisory system. In: Hippe ZS et al (eds) Human-computer systems interaction: backgrounds and applications Springer, Heidelberg

19. Kluska-Nawarecka S, Wilk-Kolodziejczyk D, Reguslki K (2011) Practical aspects of knowledge integration using attribute tables generated from relational databases, computational collective intelligence - technologies and applications, Springer Lecture Notes in Computer Science

20. Górny Z, Kluska-Nawarecka S, Wilk-Kolodziejczyk D et al (2015) Methodology for the construction of a rule-based knowledge base enabling the selection of appropriate bronze heat treatment parameters using rough sets. Arch Metall Mater 60:309-315. doi:10. 1515/amm-2015-0050

21. Kluska-Nawarecka S, Wilk-Kolodziejczyk D, Dajda J et al (2014) Computer-assisted integration of knowledge in the context of identification of the causes of defects in castings. Arch Metall Mater 59:743746. doi:10.2478/amm-2014-0124

22. Kluska-Nawarecka S, Regulski K, Krzyżak M et al (2013) System of semantic integration of non-structuralized documents in natural language in the domain of metallurgy. Arch Metall Mater 58:927930. doi:10.2478/amm-2013-0103

23. Kluska-Nawarecka S, Sniezynski B, Parada W et (2014) The use of LPR (logic of plausible reasoning) to obtain information on innovative casting technologies. Arch Civ Mech Eng 14:25-31 
24. Gorny Z Kluska-Nawarecka S, Wilk-Kolodziejczyk D (2013) Heuristic models of the toughening process to improve the properties of non-ferrous metal alloys. Arch Metall Mater 58:849-852

25. Glowacz A, Glowacz W, Glowacz Z et al (2015) Recognition of armature current of DC generator depending on rotor speed using FFT, MSAF-1 and LDA. Maintenance Reliability 17:64-69

26. David J, Švec P, Frischer R et al (2014) The computer support of diagnostics of circle crystallizers. Metalurgija 53:193-196

27. David J, Jancíiková Z, Frischer R, et al (2013) Crystallizer's desks surface diagnostics with usage of robotic system. Arch Metall Mater 58:907-910

28. Wilaszek K, Wojcik T, Oplainski A et al (2012) Internet identity analysis and similarities detection. Multimedia Communications, Services and Security, Berlin, pp 369-379

29. TurekW, Opalinski A, Kisiel-Dorohnicki M et al (2011) Extensible web crawler - towards multimedia material analysis. Multimedia Communications, Services and Security, Berlin, pp 183-190

30. Olejarczyk-Wożeńska I, Adrian H, Adrian A et al (2012) Parametric representation of TTT diagrams of ADI cast iron. Arch Metall Mater 57:981-986. doi:10.2478/v10172-012-0065-9

31. Olejarczyk-Wożeńska I, Adrian A, Mrzyglod B et al (2014) Mathematical model of the process of pearlite austenitization. Arch Metall Mater 59:613-617

32. Kmiec M, Glowacz A, Dziech A et al (2012) Towards robust visual knife detection in images: active appearance models initialised with shape-specific interest points. Multimedia Communications, Services and Security, Communications Computer Information Science 287:148-158
33. Witten I, Frank E (2000) Data mining: practical machine learning tools and techniques. Morgan Kaufmann, New York

34. Sztangret L, Szeliga D, Kusiak J et al (2012) Application of inverse analysis with metamodelling for identification of metal flow stress. Can Metall Q 51:440-446. doi:10.1179/1879139512Y. 0000000035

35. Rauch L, Sztangret 1, Pietrzyk M (2013) Computer system for identification of material models on the basis of plastometric tests. Arch Metall Mater 58:737-743

36. Tomar D, Agarwal S (2015) A comparison on multi-class classification methods based on least squares twin support vector machine. Knowl Based Syst 81:131-147

37. Li Yet, Yun Li, Yan Gao at al (2013) Fault diagnosis of metallurgical machinery based on spectral kurtosis and GA-SVM. Adv Mater Res 634-638:3958-3961. doi:10.4028/www.scientific.net AMR.634-638.3958

38. Peng S, Hua Q, Chenb Y et al (2015) Improved support vector machine algorithm for heterogeneous data. Pattern Recogn 48: 2072-2083

39. Widodo A, Yang B (2007) Application of nonlinear feature extraction and support vector machines for fault diagnosis of induction motors. Exp Sys App 33:241-250

40. Yuan S, Chu F (2007) Fault diagnosis based on support vector machines with parameter optimisation by artificial immunisation algorithm. Mech Syst Signal Process 21:1318-1330

41. Laurain Vet, Tóthc R, Pigad D al (2015) An instrumental least squares support vector machine for nonlinear system identification. Automatica 54:340-347 